\title{
O JUDICIÁRIO E O ATO INSTITUCIONAL №5: REPRESSÃO E ACOMODAÇÃO EM 1968
}

\author{
Mateus Gamba Torres ${ }^{1}$
}

RESUMO: O Ato Institucional $\mathrm{n}^{\circ} 5$ chamou a atenção para o autoritarismo escancarado, defesa da "revolução", princípios da doutrina de segurança nacional e fechamento do regime. O judiciário se sentiu acuado com o ato, porém desde o princípio do golpe nada fez para impedi-lo. Os ministros do STF ou apoiaram ou simplesmente preferiram o silêncio por medo de perderem seus cargos. Posteriormente a cassação os ministros do Supremo foram substituídos por juristas apoiadores do golpe e do sistema instalado. O artigo trata do judiciário e sua relação direta com a ditadura, especialmente o STF, que para preservar sua "autonomia" sempre esteve presente a apoiando os atos decisórios da ditadura instalada.

Palavras-chave: Judiciário. STF. Ditadura. AI-5.

\section{THE JUDICIARY AND INSTITUTIONAL ACT NO. 5: REPRESSION AND ACCOMMODATION IN 1968}

ABSTRACT: The Institutional Act $\mathrm{n}^{\circ} .5$ drew attention to open authoritarianism, defense of the "revolution," principles of the doctrine of national security, and closure of the regime. The judiciary felt attached to the act, but from the beginning of the coup he did nothing to prevent it. The ministers of the STF either supported or simply preferred silence for fear of losing their positions. After the cassation, the ministers of the Supreme were replaced by jurists who supported the coup and the installed system. The article deals with the judiciary and its direct relation with the dictatorship, especially the STF, that to preserve its "autonomy" was always present supporting the decisive acts of the installed dictatorship.

Keywords: Judiciary. STF. Dictatorship. AI-5.

\section{EL PODER JUDICIAL Y EL ACTA INSTITUCIONAL N 5: REPRESIÓN Y ACOMODACIÓN EN 1968}

RESUMEN: El acto institucional $\mathrm{n}^{\circ} 5$ llamó la atención sobre el autoritarismo abierto, la defensa de la "revolución", los principios de la doctrina de seguridad nacional y el cierre del

\footnotetext{
${ }^{1}$ Professor Adjunto II da Universidade Federal da Fronteira Sul - UFFS, em exercício na Universidade de Brasília - UNB. Doutor em História pela Universidade Federal do Rio Grande do Sul- UFRGS. Endereço eletrônico: mateustorres@unb.brou gambatorres@gmail.com.
} 
régimen. El judío se sintió acosado con el acto, pero desde el principio del golpe no hizo nada para impedirlo. Los ministros del STF o apoyaron o simplemente prefirieron el silencio por miedo a perder sus cargos. Posteriormente la casación los ministros del Supremo fueron sustituidos por juristas apoyadores del golpe y del sistema instalado. El artículo trata del judicial y su relación directa con la dictadura, especialmente el STF, que para preservar su "autonomía" siempre estuvo presente apoyando los actos decisorios de la dictadura instalada.

Palavras Clave: Judicial, STF, Dictadura, AI-5

\section{O Quinto Ato}

O Ato Institucional $n^{\circ} 5$ foi a inserção definitiva da doutrina da segurança nacional na legislação brasileira. Os poderes quase absolutos concedidos ao Presidente da República foram novamente explicados, a quem pudesse interessar, em sua exposição de motivos.

No primeiro parágrafo do ato, chama atenção a importância dada ao "combate à subversão e às ideologias contrárias a tradições do nosso povo”. (BRASIL, 1968)

Que tradições eram essas? A que se referia esse ato? Isso pode ser respondido com as palavras de um teórico da segurança nacional, Golbery do Couto e Silva. Um dos seus argumentos contra o comunismo no Brasil era de que este iria contra a nossa tradição cristã $e$ democrática.

O Brasil é também uma nação que, pela sua origem cristã e os valores democráticos e liberais que substanciam a cultura ainda em germe nesta fronteira em expansão, integra o Mundo do Ocidente, hoje, como nunca, ameaçado também pelo dinamismo imperialista e o imperialismo ideológico da civilização materialista que tem seu fulcro esteado no coração maciço da Eurásia. (SILVA, 1967)

O AI-5 citava o AI-1 nos objetivos de reconstrução econômica, financeira, política e moral do Brasil, para resolver problemas relativos à restauração da ordem interna. Os signos utilizados pela lei se identificam com a Doutrina da Segurança Nacional. A integração, o bem-estar, o progresso e a soberania, objetivos a serem alcançados para uma sociedade segura, segundo essa Doutrina, constam no quarto parágrafo da exposição de motivos do AI5 .

\footnotetext{
Considerando que, assim, se torna imperiosa a adoção de medidas que impeçam que sejam frustrados os ideais superiores da Revolução, preservando a ordem, a segurança, a tranqüilidade, o desenvolvimento econômico e cultural e a harmonia política e social do País, comprometidos por processos subversivos e de guerra revolucionária. (BRASIL, 1968)
}

A ordem era impedir qualquer manifestação destoante. A Constituição deveria, para funcionar conforme as necessidades do regime, atribuir poderes quase ilimitados ao Presidente da República em nome da tradição cristã e democrática do povo brasileiro, de 
modo a garantir o desenvolvimento econômico e cultural, e uma harmonia política e social. (BRASIL, 1968)

A Doutrina da Segurança Nacional foi, assim, mais do que constitucionalizada, foi institucionalizada. Ou seja, os princípios da segurança nacional entrelaçavam-se na cultura política da sociedade brasileira, e passaram a ser fundamento para qualquer mudança ou alteração constitucional, como foi o AI-5, transcendendo a mera dimensão jurídica.

A entrada em vigor do AI-5 foi considerado o mais repressivo dos atos no campo jurídico brasileiro, incluindo novamente o STF, com as aposentadorias compulsórias de ministros, a presença nos textos jurídicos de argumentos e expressões típicas da Doutrina de Segurança Nacional e, ainda, a forma como o novo contexto pode ser percebido nas decisões dos recursos ordinários analisados pelo Supremo.

Osvaldo Trigueiro, em seu livro, traz a opinião de alguns dos ministros do STF que viveram as mudanças efetuadas pelos militares após o Ato Institucional $\mathrm{n}^{\circ} 5$.

O ex-Ministro Evandro Lins e Silva expressa sua opinião em seu livro de memórias sobre o período O salão dos passos perdidos lançado em 1997 (2013). Maria Helena Moreira Alves, em Estado e Oposição no Brasil, mostra tanto o desenvolvimento da Doutrina de Segurança Nacional quanto as modificações institucionais pós AI-5; (2005) e Swensson Júnior (2006) mostra as muitas relações entre os ministros do Supremo e o regime ditatorial.

Examinadas como fonte, as decisões tomadas pelo STF logo após a decretação do Ato Institucional $\mathrm{n}^{\circ} 5$, por meio dos recursos ordinários criminais julgados pelo Tribunal entre os anos de 1968 a 1970 (do Ato Institucional no 5 até o início do Governo Médici), é possível esclarecer como o STF se posicionou frente à suspensão de fato da Constituição de 1967, como reagiu à intervenção do Executivo, quando da aposentadoria compulsória de alguns de seus ministros e como conciliou os conceitos políticos do regime e o discurso de autonomia.

Existia menção ao fim do habeas corpus nos crimes contra a segurança nacional, se outros órgãos do campo jurídico (Ministério Público, OAB) em suas defesas e acusações fizeram menção a tais aposentadorias, e se os ministros constatam a perda desta autonomia em suas decisões e se tentaram defendê-la ou se simplesmente aceitaram as leis de exceção e atos institucionais.

\section{O Ato Institucional $n^{0}$ 5: a subordinação entre poderes}

Dentre os poderes atribuídos ao Presidente da República pelo Ato Institucional $\mathrm{n}^{\mathrm{o}} 5$ estavam: a) fechar o Congresso Nacional e as assembleias estaduais e municipais; b) cassar 
mandatos eleitorais de membros dos poderes Executivo e Legislativo em todos os níveis; c) suspender por dez anos os direitos políticos dos cidadãos; d) decretar estado de sítio sem qualquer dos impedimentos fixados na Constituição de 1967. O ato também previa a suspensão da garantia de habeas corpus em todos os processos referentes a crimes contra a Segurança Nacional e a proibição de apreciação pelo Judiciário de recursos impetrados por pessoas acusadas em nome do AI-5. (BRASIL, 1968)

Tais poderes foram transformados em medidas que atingiram fortemente o Poder Judiciário, pois mesmo que a atribuição à Justiça Militar dos julgamentos de crimes relacionados à segurança nacional tivesse sido confirmada pela Constituição vigente, havia ainda a alternativa de solicitar habeas corpus ao STF em caso de prisão ilegal.

A suspensão do habeas corpus nos casos considerados atentatórios à segurança nacional foi a grande e perversa novidade do AI-5. Cidadãos poderiam agora simplesmente ficar presos ilegalmente e, ainda sim, não haveria a possibilidade de apreciação da legalidade de sua prisão. A garantia constitucional do habeas corpus ainda existia para aqueles que cometessem outros crimes.

Em 30 de dezembro de 1968 foi divulgada a primeira lista de cassações do AI-5, com onze deputados federais. (BRASIL, 1968) A segunda lista, de dezenove de janeiro de 1969, incluiu dois senadores, 35 deputados federais e três ministros do STF. Para o Judiciário, isso foi um golpe inesperado. Foram aposentados compulsoriamente os Ministros Evandro Lins e Silva, Hermes Lima e Victor Nunes Leal. (FOLHA de São Paulo, 2013)

As cassações podem ter sido consequência de um não enfrentamento inicial do STF em relação ao avanço do poder do Executivo. O Supremo, de acordo com a análise de Swensson Junior, em nenhum momento divergiu da vigência de atos institucionais.

\footnotetext{
Durante o regime militar de 1964, ao aceitarem a validade dos atos institucionais e da legislação de segurança Nacional, os Ministros do STF optaram por uma postura pragmática, que evitou, por algum tempo, o enfrentamento direto com os militares e provável cassação de vários Ministros (SWENSSON JUNIOR, 2006).
}

A aceitação da situação golpista pelo Judiciário pode ter se tornado, no contexto da decretação do AI-5, uma arma contra ele próprio. A partir do momento em que o Judiciário aceitou a legalidade de atos institucionais e do golpe de Estado, os ministros não poderiam questionar a legalidade do ato que cassava alguns entre eles. A cassação de tais ministros já vinha sendo exigida, segundo Swensson Junior, desde o golpe de Estado. De acordo com o autor, "Evandro Lins e Silva e Hermes Lima, que haviam sido ministros e eram homens de confiança de João Goulart, e Victor Nunes Leal, que tinha estreita ligação com Juscelino só 
não foram cassados em virtude do cargo que ocupavam.” (SWENSSON JÚNIOR, 2006) Ainda segundo Swensson Junior,

\begin{abstract}
Um dos porta-vozes do grupo era o jornal O Estado de São Paulo, que pedia a cassação dos Ministros mais identificados com o governo deposto. No editorial "Expurgo no âmbito do Judiciário", de 14 de abril de 1964, o jornal cobrava a cassação dos Ministros Hermes Lima e Evandro Lins e Silva, que seriam "elementos que se empenharam na campanha de agitação reformista". (SWENSSON JÚNIOR, 2006)
\end{abstract}

A não cassação de ministros do STF foi um indicativo de que a manutenção do funcionamento do Judiciário e a preservação de sua autonomia foram necessárias, no momento do golpe, para a legitimidade do novo regime.

Evandro Lins e Silva, em seu livro O salão dos passos perdidos, comenta que o General Castelo Branco, em sua primeira visita ao Supremo depois do golpe, cumprimentou cordialmente os três ministros que seriam cassados anos depois, não dando a impressão de que os mesmos estivessem na mira dos golpistas (SILVA, 2013).

Segundo Swensson, os ministros cassados identificavam-se cada vez mais com a defesa das liberdades civis e com as concessões de habeas corpus às pessoas acusadas de subversão, o que desagradava o governo. Explica o autor que "até a decretação do AI-5, em 13 de dezembro de 1968, os ministros defensores dos direitos civis conseguiram fazer prevalecer suas posições, em decisões cada vez mais apertadas" (SWENSSON JÚNIOR, 2006).

Ângela Moreira, em estudo sobre a justiça e a ditadura militar, aponta que a atuação mais liberal de determinados ministros do Supremo, bem como alguns juízes, era vista como um obstáculo às pretensões punitivas do regime. O quadro de conflito aberto entre Executivo e Judiciário, de acordo com a autora, ganhou expressão máxima com as edições do AI-5 e do AI-6. Essa nova onda punitiva produziu resultados significativos no Judiciário, pois promoveu o desligamento de figuras públicas que não concordavam com os direcionamentos do governo ditatorial de Costa e Silva (SILVA, 2011).

A cassação deixou profundas marcas nos Ministros. Evandro Lins e Silva declarou sua indignação ao comentar, posteriormente, tal penalidade:

Em 13 de Dezembro de 1968, o Presidente da República baixou o Ato Institucional 5, que extinguiu as garantias do Poder Judiciário. Instalou-se uma férrea ditadura, submetidos os parlamentares, os Juízes e todos os cidadãos brasileiros aos caprichosos desígnios do chefe do regime autoritário instituído com poderes absolutos e ilimitados. (...) Foi uma afronta menos a nós do que à própria Corte, esta daí por diante despojada das prerrogativas que são o alicerce de sua independência e proibida de apreciar os atos do Poder Executivo calcados no ato Institucional. (...) 
Ao mesmo tempo em que excluía do Supremo três dos seus Juízes, o Governo privara os demais de suas garantias e impunha-lhe a capitis diminutio de retirar-lhe atribuições que eram, como o são no regime democrático, apanágio de sua existência. (STF, 2013)

O discurso do ministro estabelece duas relações distintas sobre o discurso de inviolabilidade do Judiciário. Primeiro, estipulando que o ato acabava com uma das principais prerrogativas desse poder, presente em praticamente todas as constituições republicanas: a inafastabilidade do Poder Judiciário na apreciação dos atos do Executivo do ponto de vista constitucional. Nesse caso, o ministro estava se referindo especificamente ao Ato Institucional $\mathrm{n}^{\mathrm{o}} 5$, ato que posteriormente foi fundamento para a sua cassação. Porém, essa prerrogativa estipulada pelos militares já estava presente desde o Ato Institucional $\mathrm{n}^{\circ} 1$. Desde o primeiro ato, o Executivo excluiu da apreciação do Judiciário qualquer decisão sua baseada nos atos institucionais. A crítica, entretanto, somente foi feita após tal exclusão atingir diretamente seus membros, sendo a impossibilidade de apreciação dos atos do Executivo considerada, agora, um despojamento da independência do Judiciário.

A segunda relação estabelece que o ato de cassação seria grave não só pela individualidade do ato em si, mas também pela afronta ao Judiciário como um todo. A cassação de três Ministros diminuiria a atuação do Judiciário, submetendo-o às decisões do Poder Executivo, que se baseara na suspensão da garantia de vitaliciedade estipulada no Ato Institucional $n^{\circ} 5$ para cassar os ministros.

O fim da vitaliciedade já vinha acontecendo desde o golpe de Estado, não sendo nenhuma novidade estipulada pelo quinto Ato. No Ato Institucional $\mathrm{n}^{\circ} 1$ também havia suspendido tal garantia, mas como ainda não havia sido punido nenhum membro das Cortes superiores, parecia que isso não era motivo de crítica até então. Ou seja, a novidade era a utilização do ato para cassar ministros do STF, isso, segundo Evandro Lins e Silva, merecedor de críticas. Mas tais opiniões contrárias às cassações não ocorreram quando as classes atingidas eram outras que não a sua (professores universitários, juízes de $1^{\circ}$ grau e outras que também gozavam da garantia da vitaliciedade à época).

Para o jurista Osvaldo Trigueiro do Vale, a cúpula do Poder Judiciário ficou enfraquecida com o AI-5 e com a cassação dos ministros:

Haveria uma mudança na sua conduta jurisprudencial. A modificação paulatina, porém crescente, do direito escrito por parte do sistema revolucionário e o uso dos dispositivos punitivos do AI-5, contra três Ministros do Supremo reduziriam radicalmente a importância da cúpula judiciária brasileira. (VALE, 1976) 
Assim, a queixa feita pelo ministro também é acompanhada pela análise do professor. O Judiciário estava enfraquecido pelo poder militar instalado no governo e a prova concreta desta diminuição de independência foi a cassação dos ministros do Supremo.

Segundo Trigueiro, “o sistema político da Revolução se comprimiu com a edição de novos atos institucionais, relegando a um segundo plano as conquistas constitucionais de 1967. Desse novo quadro jurídico-político, como não poderia deixar de ser, o Supremo fazia parte" (VALE, 1976). Nessa avaliação, o autor inclui o Judiciário no sistema político e assim as expulsões estariam diretamente relacionadas à falta de uma sintonia entre o que pensa o governo ditatorial e os ministros cassados.

Após a aposentadoria compulsória dos ministros mencionados, o Ministro Antônio Gonçalves de Oliveira, então Presidente do STF, renuncia, e entra com o seu pedido de aposentadoria, em forma de protesto. O Ministro Antônio Carlos Lafayette de Andrada, com a aposentadoria compulsória de Victor Nunes Leal e administrativa de Gonçalves de Oliveira, seria galgado à presidência do STF. Ele também pede aposentadoria. Os dois pedidos foram assim avaliados por Trigueiro: “Ambos mineiros, um deles descendente de José Bonifácio, foram os únicos funcionários de alto nível dos poderes republicanos a se valerem do espírito de renúncia para impedir o prosseguimento da confusão entre a história do regime e suas biografias". (GASPARI, 2002).

\section{STF - reação parcial à autonomia violada}

Nesse momento dois ministros do Supremo se "rebelam" contra o Executivo. E isso acontece quando o corpo no qual estão inseridos, STF, é ferido em sua autonomia. Alguns juízes de primeira instância já haviam sido aposentados, postos em disponibilidade, ou até demitidos, e isso foi aceito pelo corpo jurídico como um todo e consequentemente pelos ministros do STF. Foi apenas após a cassação dos ministros que o Judiciário, entenda-se os membros da corte mais alta da Justiça, considerou que sua autonomia foi violada (CAMARA DOS DEPUTADOS, 2013).

O pressuposto da autonomia do Judiciário em relação aos outros poderes ou às forças de pressão da sociedade é, segundo Bourdieu, elemento essencial na Constituição do campo jurídico. Segundo o sociólogo,

a reivindicação da autonomia absoluta do pensamento e da ação jurídicos afirma-se na Constituição em teoria de um modo de pensamento específico, totalmente liberto do peso social, e a tentativa de Kelsen para criar uma "teoria pura do direito" não passa do limite ultra-consequente do esforço de todo o corpo dos juristas para construir um corpo de doutrinas e de regras completamente independentes dos 
constrangimentos e das pressões sociais, tendo nele mesmo o seu próprio fundamento. (BOURDIEU, 2010)

Os ministros de Supremo estariam no topo da pirâmide do corpo de juristas, onde as doutrinas jurídicas, regras, normas formariam um escudo a pressões externas. Ao Judiciário caberia julgar imparcialmente as leis e todo o corpo social deveria aceitar suas decisões.

O governo ditatorial, na atitude de manter o STF aberto e os mesmos ministros trabalhando, queria demonstrar que sua revolução era carregada de legitimidade. Afinal, manteve um Tribunal Superior, o qual poderia julgar o regime futuramente (não pelos atos da revolução, visto que os atos institucionais estavam fora de apreciação judicial). Esta revolução daria legitimidade aos membros do $\mathrm{STF}$, mesmo que nomeados por outros presidentes da República.

Ao aposentar compulsoriamente três ministros do Supremo, e tendo dois se aposentado em solidariedade, o poder Executivo ficou com cinco vagas abertas e, ao invés de preenchê-las, resolveu extingui-las.

Em 1969 assume a presidência o General Emilio Garrastazu Médici, ex-comandante do III Exército sediado em Porto Alegre e ex-chefe do Sistema Nacional de Informações do Governo Costa e Silva. (BIBLIOTECA da Presidência da República, 2014) Médici continuou com a sanha repressiva de seu antecessor no momento em que o Brasil vivia o momento do milagre econômico. ${ }^{2}$

No governo Médici, o Supremo manteve o número habitual de ministros e, segundo Élio Gaspari,

(...) entre os onze sobreviventes lá continuaram Adaucto Lúcio Cardoso e Aliomar Baleeiro, instrumentistas da "banda de música" da UDN, ferozes adversários daquilo que poderia ter sido a ditadura de João Goulart. Meses depois, juntou-se a eles Bilac Pinto, o responsável pela introdução do conceito de "guerra revolucionária" no vocabulário político civil. (GASPARI, 2002).

Adaucto Lúcio Cardoso e Aliomar Baleeiro tinham sido nomeados com a criação das vagas do AI-2, o que torna compreensível sua permanência. Ambas as escolhas relacionam-se com a participação ativa dos juristas em atividades políticas anteriores ao golpe.

O Ministro Adaucto Lúcio Cardoso, era bacharel em Direito, formado pela Faculdade do Rio de Janeiro em 1927. Foi um dos autores em 1943 do Manifesto dos Mineiros, em que

\footnotetext{
${ }^{2}$ Milagre Econômico foi o momento durante o período ditatorial que o Produto Interno Bruto brasileiro cresceu com a uma taxa média de 10\% ao ano durante o governo Médici (1969-1974). O aumento da taxa de crescimento devia-se ao aumento do total de investimentos estrangeiros e a um amplo programa de investimentos do Estado, aplicando fundos de instituições internacionais de crédito. Este último fator provocou elevação da dívida externa, que um de 3,9 bilhões de dólares em 1968 saltou para mais de 12,5 bilhões de dólares em 1973. Conforme: ALVES, Maria Helena Moreira. Estado e oposição no Brasil: 1964-1984. Bauru, SP, Edusc, 2005.
} 
diversas personalidades do Estado de Minas Gerais, criticavam o Estado Novo, exigiam a volta da democracia no país. Em 1944, foi um dos fundadores do chamado Movimento de Resistência Democrática, opositor da ditadura do Estado Novo e do Governo Vargas. Sua militância política fez com que em 1947, fosse eleito vereador no Distrito Federal pela União Democrática Nacional (UDN). Em 1954 e 1958, foi eleito deputado federal pelo Distrito Federal, pela UDN. Com a criação do estado da Guanabara, passou a representar na Câmara a nova unidade da Federação. Em 1962, reelegeu-se deputado federal pela Guanabara (CPDOC, 2014).

Com relação ao golpe de 1964, o então deputado Adauto Lúcio Cardoso participou ativamente dos preparativos do movimento que depôs o presidente João Goulart. Desde novembro de 1963, mantinha contatos com o General Humberto Castelo Branco, chefe do Estado-Maior do Exército (EME), e com outros chefes militares, o que lhe valeu em 1965 a presidência do Bloco Parlamentar Revolucionário, agrupamento suprapartidário de parlamentares que apoiavam o novo regime, sendo, em 1966, eleito presidente da Câmara dos Deputados. Com o bipartidarismo filiou-se à ARENA, elegendo-se deputado federal pela legenda em 1966, não chegando a tomar posse do cargo, pois foi nomeado pelo General Castelo Branco ministro do STF (CPDOC, 2104).

Com essa militância política não houve surpresa em sua nomeação. Apesar de sua vinculação à UDN, teve algumas decisões favoráveis à oposição. Em 1968 votou a favor da concessão de habeascorpus ao líder estudantil carioca Vladimir Palmeira, preso em consequência das manifestações de rua que então liderava, e de um habeas corpus preventivo ao ex-chefe do Gabinete Civil do governo Goulart, Darcy Ribeiro, que também se encontrava detido. Além disso, em 1971 renunciou ao cargo de ministro do Supremo, após ter sido vencido na votação sobre a inconstitucionalidade do Decreto-Lei ${ }^{\circ} 1.077$, do Presidente Emílio Garrastazu Médici, que instituía a censura prévia a livros e periódicos. (CPDOC, 2014)

O debate sobre o decreto, na verdade, nem chegou a entrar no mérito da constitucionalidade no STF. O MDB ingressou com uma arguição de inconstitucionalidade contra o decreto. O Procurador-Geral de Justiça determinou o arquivamento da referida arguição por considerá-la descabida. O MDB, por sua vez, ingressou com a Reclamação 849, argumentando que somente o Supremo poderia determinar se a ação era ou não cabível, não sendo essa uma prerrogativa do Procurador Geral de Justiça. O Ministro Adauto Lúcio Cardoso foi o único voto contrário à constitucionalidade do decreto. A votação estabeleceu ao 
Procurador-Geral da República a competência exclusiva de encaminhar ou não as ações de inconstitucionalidade ao STF. Ou seja, antes da ação ser encaminhada ao STF quem decidia se a inconstitucionalidade iria ser votada no plenário do STF era o Procurador-Geral de Justiça. Cardoso, por fim, resolveu renunciar ao cargo, não por ser contra ou a favor da censura prévia, mas sim pela restrição aos poderes do próprio STF. Ele renunciou por não concordar que o Procurador-Geral de Justiça decidisse previamente sobre a constitucionalidade ou não de um ato, e por acreditar que isso deveria ser decidido pelo Supremo. (STF, 2014)

Pelo conjunto de informações cabe destacar que o Ministro lutava para a manutenção do discurso de imparcialidade do Supremo, o que não foi seguido por seus colegas que não aceitaram nem mesmo entrar no mérito sobre a constitucionalidade ou não de um decreto que determinava a censura prévia no país.

Aliomar Baleeiro, o outro ministro nomeado com a criação das vagas do AI-2, era formado em Direito pela Faculdade de Ciências Jurídicas e Sociais da Bahia em 1925, dedicou-se à advocacia e ao jornalismo, fazendo oposição ao governo Vargas, e tendo sido eleito deputado à Assembleia Estadual Constituinte da Bahia, em 1934. Com o golpe do Estado Novo, retirou-se da política, dedicando-se novamente à advocacia. Em 1945 fundou em seu escritório, em Salvador, a UDN baiana. Também em 1945 elegeu-se deputado pela Bahia à Assembleia Nacional Constituinte na legenda da UDN. Reelegeu-se deputado em 1950 e 1954, sempre pela UDN. Foi grande opositor dos governos Vargas e, posteriormente, de Juscelino Kubitschek.

Não conseguindo reeleger-se à Câmara Federal, foi Secretário da Fazenda da Bahia, porém deixou o cargo ao se eleger deputado pelo Estado da Guanabara. Reelegeu-se deputado em 1962 e foi um radical opositor a João Goulart. Manteve-se na Câmara Federal desde o golpe de Estado até sua nomeação por Castelo Branco como ministro do STF em 25 de novembro de 1965. Foi presidente do Supremo entre 1971 e 1973, aposentando-se em 1975. (CPDOC, 2014)

O único ministro nomeado anteriormente ao golpe e que ainda permanecia no Supremo, depois do AI-5, era o catarinense Luiz Gallotti. Esse ex-presidente do STF não só permaneceu como assumiu interinamente a presidência do STF perante a crise institucional resultante dos pedidos de aposentadoria mencionados. Não há registros de que tenha demonstrado qualquer rebeldia em relação à cassação dos colegas. 
O prédio do Tribunal de Justiça de Santa Catarina, inaugurado em três de março de 1975, chama-se Luiz Gallotti, em homenagem ao ministro catarinense que nunca foi incomodado pelo regime por sua postura com relação à ditadura. Um dos exemplos dessa postura foi o caso da prisão, em 1964, de Francisco Julião, e de seu pedido de habeas corpus. Luiz Gallotti, como relator do Habeas corpus $\mathrm{n}^{\circ} 42.560$, indeferiu o pedido "sob o fundamento de que estava justificado o suposto excesso de prazo de prisão do paciente, haja vista a complexidade dos fatos imputados e a imensa quantidade de co-réus presos". (STF, 2013) Os outros ministros, no entanto, votaram no fundamento de Evandro Lins e Silva, que divergiu do relator. $\mathrm{O}$ caso foi assim relatado pelo próprio jurista.

\begin{abstract}
A divergência vencedora foi inaugurada pelo Ministro Evandro Lins, sob o fundamento de que houve excesso de prazo e de que o art. 43 da Lei de Segurança do Estado se aplicava à Justiça Militar e determinava que a prisão preventiva fosse pelo prazo máximo de sessenta dias. O paciente encontrava-se preso preventivamente havia mais de um ano. Ademais, rejeitou-se a grande quantidade de co-réus, como justificativa aceitável para o excesso de prazo na formação da culpa. À exceção do Relator, os demais Juízes da Corte acompanharam o voto do Ministro Evandro Lins e concederam a ordem para que Francisco Julião respondesse o processo em liberdade (grifo nosso) (STF, 2013).
\end{abstract}

Essa situação exemplifica por que Evandro Lins e Silva foi aposentado compulsoriamente e Luis Gallotti assumiu interinamente a Presidência do Supremo após as cassações que se seguiram ao AI-5. Mesmo que Evandro Lins e Silva não tenha se oposto ao golpe num primeiro momento, suas decisões em relação aos presos políticos foram um pouco mais legalistas e menos revolucionárias do que era esperado pelo governo. Assim, ele agiu diferentemente de Luis Gallotti, o qual não hesitou em condenar um líder político mesmo que ele estivesse há mais de um ano preso e sem culpa formada.

O esforço de Gallotti foi recompensado pelo regime. Luis Gallotti havia sido nomeado para o STF em 1949, pelo Presidente Eurico Gaspar Dutra, anticomunista assumido. Seu filho, Luiz Octávio Pires e Albuquerque Gallotti, também foi ministro do Supremo, nomeado em 1984 pelo General Presidente João Figueiredo, o que é indicativo da importância da formação familiar na escolha dos membros do Judiciário. Bourdieu chama a atenção para a afinidade do habitus desse grupo, que está ligada a formações familiares e escolares semelhantes e a uma identificação entre as visões do mundo da classe dominante e aquelas dos membros do corpo jurídico. (BOURDIEU, 2010) Ainda para Bourdieu, "a pertença dos magistrados à classe dominante está atestada em toda parte". (BOURDIEU, 2010) E tal pertença possui uma explicação: 
o facto de, pelo menos até um período recente, a fortuna garantida por uma origem rica ser a condição de independência econômica e mesmo do eto ascéticos que são constituídos, de certo modo, pelos atributos estatutários de uma profíssão consagrada ao serviço do Estado, contribui para explicar, com os efeitos próprios da formação profissional, que a neutralidade proclamada e a aversão altamente professada a respeito da política não excluam, pelo contrário, a adesão a ordem estabelecida (BOURDIEU, 2010).

Dentro dessa classe economicamente dominante, seus membros não precisariam do salário do Estado, visto que já eram de uma classe social de homens ricos. Essas pessoas eram consideradas, ao mesmo tempo, altos funcionários do Estado, mas detentores de uma independência, uma autonomia, que os desvincularia da política em suas decisões. Conforme afirma Bourdieu, essa condição de classe, ao contrário de tornar autônomos os membros do Judiciário, os colocava como defensores da ordem estabelecida, a mesma ordem que os manteria como homens ricos e membros da classe dominante.

Com relação a Bilac Pinto, sua atuação como deputado federal da UDN, partido que foi o grande apoiador do golpe de Estado, lhe rendeu a indicação ao Supremo, bem como sua atuação como divulgador do conceito de Guerra Revolucionária no dicionário político brasileiro, por conta de um livro homônimo publicado em 1964. (PINTO, 1964) Em 1965, foi eleito presidente da Câmara de Deputados. De 1966 a 1970 foi embaixador do Brasil na França, quando então foi nomeado ministro do Supremo. Boa parte de suas ideias estão expressas no livro Guerra Revolucionária, (PINTO, 1964) em que explica os perigos deste tipo de guerra e como o Brasil, com o golpe de 1964, se livrou deles. Na obra, Bilac também defende que se deveria combater tudo o que fosse considerado aderente à ideologia comunista/subversiva, a qual pregava a guerra revolucionária como meio de alcance do poder.

\begin{abstract}
A "guerra revolucionária" consiste no conjunto das medidas e ações, militares ou não, decididas e aplicadas metodicamente pela direção central do comunismo contra um Estado não-comunista.(...) A 'guerra revolucionária' tem permitido à U.R.S.S. dominar numerosos países sem exército e sem armas convencionais, mediante o simples emprego de técnicas psicológicas que visam simultaneamente conquistar o apoio da opinião pública para a ideologia básica escolhida (no Brasil essa ideologia básica é constituída pelas 'Reformas de Base' e especialmente pela 'Reforma Agrária'), (PINTO, 1964).
\end{abstract}

Também não foi algo estranho o ex-deputado federal pela UDN ter sido nomeado pelo ditador Médici como Ministro do Supremo. A guerra revolucionária precisava de um jurista, professor e político que definisse e trouxesse para o meio político e jurídico uma explicação para esse conceito. Uma guerra contra quem o governo e todos os brasileiros deveriam especificamente lutar. Nessa sua obra, o futuro ministro também esclarecia como seria o método de infiltração comunista no Brasil, o que justificaria a Doutrina da Segurança 
Nacional e a vigilância do governo com os opositores. Por esses conceitos já se percebe que o comunista seria alguém que tomaria mentes para seu lado e conquistaria o poder, sendo as pessoas levadas a isso por sua influência; em outras palavras, estariam sendo iludidas pelo comunista a seguirem sua doutrina.

O AI-5 representou uma demonstração de força do governo militar contra qualquer cidadão que fosse contra o regime instaurado em 1964. A aposentadoria compulsória de Evandro Lins e Silva, Hermes Lima e Victor Nunes Leal deixou clara a posição do Executivo em não admitir divergências. Tais ministros, além de considerados ligados ao governo deposto, se identificavam com as liberdades civis que foram sendo, pouco a pouco, suprimidas pelo governo militar.

Os ministros que por medo, comodismo ou até concordância com as decisões governamentais faziam de suas decisões a extensão das ideias do regime, mantiveram-se em seus cargos.

\section{Referências}

ADAUCTO Lúcio Cardoso. Disponível em: <http://cpdoc.fgv.br/producao/dossies/Jango/biografias/adauto_lucio_cardoso>. Acesso em: 15 fev. 2014.

ALIOMAR Baleeiro. Disponível em: <http://cpdoc.fgv.br/producao/dossies/AEraVargas2/biografias/aliomar_baleeiro>. Acesso em: 15 fev. 2014.

ALVES, Maria Helena Moreira. Estado e oposição no Brasil: 1964-1984. Bauru, SP, Edusc, 2005.

ATOS Institucionais: Sanções Políticas. Disponível em: <http://bd.camara.gov.br/bd/bitstream/handle/bdcamara/6384/atos_\%20institucionais_oliveira .pdf>. Acesso em; 5 ago. 2013.

BIBLIOTECA da Presidência da República. Disponível em: $<$ http://www.biblioteca.presidencia.gov.br/ex-presidentes/emilio-medici/biografia-periodopresidencial>. Acesso em: 5 fev. 2014.

BOURDIEU, Pierre. O Poder Simbólico. Rio de Janeiro: Bertrand Brasil, 13 a ed. 2010. P. 209.

BRASIL. Ato Institucional $n^{0} \mathbf{5}$, de 13 de dezembro de 1968. Disponível em: <http://www.planalto.gov.br/ccivil_03/AIT/ait-05-68.htm>. Acesso em: 5 nov. 2010.

\section{BRASIL. Decreto de 30 de dezembro de 1968, Cassação de mandatos eletivos federais e suspensão dos direitos políticos de parlamentares. Disponível em:}


<http://www2.camara.leg.br/legin/fed/decret_sn/1960-1969/decreto-36472-30-dezembro1968-548074-publicacaooriginal-63032-pe.html>. Acesso em: 10 ago. 2013.

GASPARI. Élio. A ditadura escancarada. São Paulo: Companhia das Letras, 2002.

MEMÓRIA Jurisprudencial Ministro Evandro Lins e Silva. Disponível em: <http://www.stf.jus.br/arquivo/cms/publicacaoPublicacaoInstitucionalMemoriaJurisprud/anex o/EvandroLinse Silva.pdf.>. Acesso em: 25 jan. 2013.

$\mathrm{O}$

AI-5.

Disponível

em:

<http://www1.folha.uol.com.br/folha/treinamento/hotsites/ai5/ai5/index.html>. Acesso em: 10 ago. 2013.

SILVA, Angela Moreira Domingues da. Ditadura e Justiça Militar no Brasil: a atuação do Superior Tribunal Militar (1964-1980). Tese de Doutorado. Rio de Janeiro: CPDOC/FGV, 2011, p.122.

SILVA. Evandro Lins e. $O$ salão dos passos perdidos. Disponível em: <http://apreendaapreender.files.wordpress.com/2012/05/o-salao-dos-passos-perdidos.pdf> Acesso em: 10 ago. 2013.

SILVA, Golbery do Couto e. Geopolítica do Brasil. Rio de Janeiro: José Olympio, Coleção Documentos Brasileiros, 1967.

SWENSSON JUNIOR, Walter Cruz. Os limites da liberdade. A atuação do Supremo Tribunal Federal no julgamento de crimes políticos durante o regime militar de 1964 (19641979). São Paulo: Tese. Doutorado em História, FFLCH-USP, 2006.

PINTO, Olavo Bilac. Guerra Revolucionária, Rio de Janeiro: Forense, 1964. 228 p.

RECLAMAÇÃO 849 de 10 de março de 1971. Disponível em: $<$ http://redir.stf.jus.br/paginadorpub/paginador.jsp?docTP=AC\&docID=87519>. Acesso em: 15 fev. 2014.

VALE, Osvaldo Trigueiro do. O Supremo Tribunal Federal e a instabilidade políticoinstitucional. Rio de Janeiro: Civilização Brasileira, 1976.

Recebido em setembro de 2018

Aprovado em novembro de 2018 